Revista Destaques Acadêmicos, Lajeado, v. 11, n. 4, 2019. ISSN 2176-3070

DOI: http://dx.doi.org/10.22410/issn.2176-3070.v11i4a2019.2406

http://www.univates.br/revistas

\title{
ROBÓTICA NAS SÉRIES INICIAIS DO ENSINO FUNDAMENTAL COMO FERRAMENTA PEDAGÓGICA MOTIVACIONAL
}

\author{
Daiane Andressa Hensel ${ }^{1}$, Maria Claudete Schorr ${ }^{2}$
}

Resumo: Os recursos tecnológicos estão cada vez mais incorporados em nossas atividades diárias, seja na indústria, comércio, tarefas pessoais ou na educação. Na educação é possível aprender e ensinar de diferentes maneiras desenvolvendo habilidades e competências por meio da tecnologia. Sendo assim, o objetivo deste trabalho é investigar a viabilidade da introdução da robótica como ferramenta motivadora dos estudantes do $3^{\circ}$ ano do Ensino Fundamental na realização de atividades da língua portuguesa. Para atingir o objetivo foi criado um protótipo robótico chamado Mika Robô que funciona a partir de um objeto de aprendizagem. Foi realizada uma pesquisa exploratória, a construção do protótipo robótico e um estudo de caso e para levantamento dos dados, foram empregados um pré-teste, um pós-teste, análise das respostas no objeto de aprendizagem, filmagem, além da observação espontânea e participante dos estudantes. $\mathrm{O}$ estudo de caso efetivou-se com sete estudantes do $3^{\circ}$ ano do Ensino Fundamental de uma escola municipal do interior do Rio Grande do Sul. Como resultados percebeu-se que o desempenho dos estudantes foi melhor no pós-teste, notou-se os estudantes motivados para resolver as atividades, isso foi um fator determinante na utilização do OA, tendo em vista o prêmio conforme número de acertos do desenho do Mika Robô.

Palavras-chave: Motivação. Robótica. Ensino fundamental.

\section{INTRODUÇÃO}

A escola tem o objetivo de preparar os alunos para a vida em sociedade, tendo como um dos desafios conciliar o aprendizado com o cotidiano (ZILLI, 2004). É no ensino da educação básica que são desenvolvidas as potencialidades das crianças, e a Computação tem muito a contribuir nesse desenvolvimento na sociedade atual (GORDINHO, 2009). As "disciplinas clássicas" juntamente com a Computação (RIBEIRO et al., 2011), trabalham o Pensamento Computacional

1 Acadêmica de Engenharia de Software - Universidade do Vale do Taquari - Univates

2 Docente da área da Computação - Universidade do Vale do Taquari - Univates 
que é definido como habilidades e competências na resolução de problemas (BARCELOS; SILVEIRA, 2012), sendo investigado e discutido pelo MEC (2017) na Base Nacional Comum Curricular (BNCC), documento que apresenta as aprendizagens essenciais da Educação Básica, citando o Pensamento Computacional como uma competência desenvolvida juntamente com o letramento matemático.

Estamos cada vez mais rodeados ou dependentes das tecnologias. Aliada aos ideais construtivistas, a tecnologia é uma poderosa ferramenta de ensino. Hoje, estão sendo buscados novos caminhos através das tecnologias, como o computador, a robótica ou objetos de aprendizagem informatizados, que fornecem apoio aos educadores e podem promover o desenvolvimento crítico e autônomo para as crianças (ZILLI, 2004; KONRATH et al., 2006).

Maliuk (2009) aponta que hoje a robótica é uma realidade cada vez mais acessível, desde simples dispositivos domésticos até os mais sofisticados mecanismos. A robótica educacional é utilizada, conforme Oliveira et al. (2014), para incentivar e influenciar alunos a interessar-se por disciplinas mais difíceis, abstratas, como, por exemplo, a matemática. Aliado a isso, Ribeiro et al. (2011) afirma que estimular a curiosidade natural de crianças demonstra o poder da motivação em atividades que normalmente são difíceis para elas.

A motivação num simples ambiente escolar não é algo simples e fácil de manter, visto que os estudantes se sentem mais atraídos pelos recursos que a tecnologia proporciona (KNÜPPE, 2006). O fenômeno da gamificação propõe inserir características da gamificação como atrativo, contribuindo no processo de ensino e aprendizagem, envolvendo e motivando as crianças assim como os jogos o fazem, construindo "[...] uma estratégia voltada à construção de experiências mais significativas" (FARDO, 2013, p. 66).

O objetivo de qualquer educador, afirma Ribeiro (2006), é encontrar ferramentas que potencializem o aprendizado e promovam motivação nas mais diversas disciplinas possíveis. E a tecnologia é um dos recursos que tem oferecido muitas esperanças à educação, pois desde muito cedo as crianças estão tendo contato com aparelhos eletrônicos, sendo necessário instruílas e influenciá-las a utilizar estes dispositivos da melhor maneira para o aprendizado. Além de dar suporte à aprendizagem, o uso das tecnologias ajuda a construir atitude, criatividade, autonomia, cooperação e comunicação.

A robótica educacional busca, segundo Ribeiro et al. (2011, apud RIBEIRO, 2006), auxiliar na aprendizagem do aluno, devido a motivação que proporciona. Neste sentido construiu-se um robô denominado Mika Robô e um objeto de aprendizagem (OA) que coloca o robô em funcionamento. O nome da proposta deu-se devido à mascote chamar-se Mika Pet. Foi realizada uma intervenção pedagógica com estudantes do $3^{\circ}$ ano do Ensino Fundamental de uma escola municipal do interior do Rio Grande do Sul. 


\section{EMBASAMENTO TEÓRICO}

Para a sociedade do século XXI a "Alfabetização digital" se torna muito importante no cenário educacional. Há diversas necessidades mudando os paradigmas da educação, devido à sociedade estar toda interconectada, participando de uma "rede de construção colaborativa" (SOBREIRA et al., 2013). A escola está passando pela mesma revolução que a sociedade, com o objetivo de aperfeiçoar a qualidade do ambiente de aprendizagem (MALIUK, 2009), porém, a "educação pública é avessa aos riscos e à inovação porque é preciso garantir que estamos fazendo o que é certo com crianças" e é necessário ter segurança no que se deve ensinar (BRACKMANN, 2017, p. 47).

A geração atual é chamada de "[...] nativos digitais [...]", pois já possui fluência em utilizar tecnologias e a interação das crianças e também dos jovens com as tecnologias alterou o seu modo de pensar e processar informações (SOBREIRA et al., 2013, p. 128; PAIVA; COSTA, 2015). De acordo com Zilli (2004, p. 14), "[...] a educação é um campo fértil para o uso da tecnologia", podendo tornar a aprendizagem mais motivadora e dinâmica. E as tecnologias contribuem para novas formas de acesso ao conhecimento e estilos de raciocínio, os quais podem ser compartilhados com o mundo. A capacidade da inteligência coletiva está mudando as relações sociais e humanas.

Contribuindo para um aprendizado mais dinâmico e significativo em conjunto com a tecnologia, surgiram os Objetos de Aprendizagem (OA), que são caracterizados como Sistemas de Informação (SI) educativos (GONÇALVES, 2002; KONRATH et al., 2006). Segundo Konrath et al. (2006, p. 2) o OA é entendido como "[...] qualquer material ou recurso digital com fins educacionais [...]" com elementos multimídia como imagens, vídeos, textos, sons e ou outros recursos digitais.

Além dos OA um novo cenário se aproxima o desenvolvimento do Pensamento Computacional (PC). O pensamento computacional vem de "computacional thinking" e é definido como habilidades e competências na resolução de problemas, utilizando-se recursos computacionais ou algoritmos como auxílio (SILVA et al., 2014; BARCELOS; SILVEIRA, 2012), sendo uma habilidade fundamental para todas as áreas, não somente a computação (FRANÇA; AMARAL, 2013). Essas habilidades e competências essenciais para a formação do cidadão da sociedade atual na Educação Básica podem ser encontradas na BNCC, que também cita a resolução de problemas, além da importância dos algoritmos nas aulas de matemática, mas não há menção alguma a programação e a robótica especificamente (MEC, 2017; PAIVA; ANDRADE, 2018).

Em muitos momentos utiliza-se a robótica como meio para o desenvolvimento do PC. A robótica faz parte inerente de nossa sociedade e cotidiano, e não podemos falar dela sem falar de robô. Os robôs estão presentes na maioria dos filmes de ficção científica, mas eles não ficam somente em nosso 
imaginário, se manifestam em nosso dia a dia desde nas formas de botões de elevador e controle remoto a máquinas industriais (MALIUK, 2009; RIBEIRO, 2006). A Robótica é conceituada como "a ciência dos sistemas" na qual ocorrem interações com o mundo real, e pode ocorrer intervenção humana ou não (ZILLI, 2004).

Além das áreas mais delicadas, a robótica vem sendo amplamente inserida em sala de aula (COSTA, 2012) e o seu uso em ambientes de ensino demonstra seu grande potencial pedagógico, de acordo com a filosofia construtivista de Papert, Piaget e Vygotsky (SOBREIRA et al., 2013). Há diversas competições de Robótica onde crianças e adultos participam, explorando essa área e aprendendo com ela (RIBEIRO, 2006).

A robótica educacional é uma ferramenta ampla, definida como um ambiente com aparelhos eletrônicos e seus sistemas, no qual são construídos e programados dispositivos automatizados por um aprendiz, com intuito de explorar diferentes áreas do conhecimento. Tendo a capacidade de comunicarse com o ambiente e realizar tarefas previamente programadas para com este meio. Tanto seu potencial pedagógico quanto a motivação impressionam educadores e estudantes (RIBEIRO, 2006; RIBEIRO et al., 2011).

O objetivo da robótica educacional não é o do domínio técnico da robótica em si, é contribuir na construção de conhecimentos, aprendendo os conceitos teóricos integrado com outras disciplinas, através do uso de suas ferramentas e na criação de artefatos e experimentos robóticos (ZANETTI et al., 2012). Os materiais utilizados para as atividades da robótica educacional podem ser kits robóticos prontos ou ainda utilizar sucatas de outros aparelhos ou reinventar algum brinquedo, construindo o seu próprio protótipo robótico a partir destes, o que requer mais trabalho e conhecimentos técnicos (RIBEIRO, 2006).

Nota-se um aumento significativo na motivação dos estudantes quando da utilização da robótica em sala de aula. Motivação é conceituada como um "processo psicológico", amparada por conjuntos de elementos afetivos e emocionais, é a sua "energia psíquica". As variáveis, ou metas para alcançar um objetivo, aliadas ao envolvimento afetivo, constituem a motivação (KNÜPPE, 2006, p. 208; ZILLI, 2004). Existem dois tipos de motivação, a intrínseca e extrínseca.

A motivação intrínseca refere-se a realizar uma atividade ou exteriorizar atitudes por fatores internos, sentimentos "[...] como prazer, orgulho, força de vontade, desafio [...]". Já a motivação extrínseca refere-se "[...] às rotinas que vamos aprendendo ao longo de nossas vidas.", na qual a meta ou variável, realizando atividades ou demonstrando atitudes, está relacionada a um evento externo, a algum objetivo palpável, "[...] uma recompensa externa, como um prêmio em dinheiro, uma medalha, um presente [...]" (KNÜPPE, 2006, p. 280; FARDO, 2013, p. 51). 
Tendo em vista a motivação do estudante, a gamificação vem de encontro com este tema. Gamificação vem da palavra em inglês gamification, junção da palavra game, jogo eletrônico, com sufixo fication que juntos remetem "[...] ao ato de fazer jogo, tornar jogo". Ela se refere ao uso de elementos de games, fora do contexto de games. No contexto educacional, é definida como a utilização de mecânicas, estética e pensamentos dos jogos eletrônicos, envolvendo as pessoas, motivando suas ações, promovendo a aprendizagem e solucionando problemas. As recompensas são elementos essenciais de jogos eletrônicos, pois servem para estimular a resolução de desafios propostos e podem influenciar os resultados de forma positiva (FARDO, 2013, p. 13).

Voltando às décadas de 50 e 60 quando surgiram os primeiros computadores, a educação seguia os ideais behavioristas, que utilizava dispositivos eletrônicos para repassar conhecimentos, com a limitação de funcionar apenas com ramificações bem definidas, mas tratado como a solução para todos problemas do ensino (RIBEIRO, 2006).

Mas os ideais mais aceitos foram o construtivismo, desenvolvido por Jean Piaget, processo intuitivo e ativo de construção, no qual o aprendiz tem o papel principal, da relação do conhecimento com o cotidiano, mostrando que a tecnologia conta com diversas ferramentas como ambientes de realidade virtual e a robótica. E o construcionismo, desenvolvido por Seymour Papert, na qual a construção reflexiva do conhecimento acontece através das coisas significativas, e tudo acontece com a ajuda do computador, impulsionando o uso da tecnologia, particularmente a robótica, na aprendizagem significativa (RIBEIRO, 2006; ZILLI, 2004).

\section{METODOLOGIA}

A metodologia de pesquisa adotada é de natureza exploratória, que busca aumentar a familiaridade e compreensão com o problema (CHEMIN, 2015). A hipótese é baseada na comparação com outros estudos (LAKATOS; MARCONI, 2003), com a justificativa de a tecnologia estar cada vez mais perto da criança, e um robô, palpável e visível na vida real pode ser um grande motivador na sua educação. Nesta proposta será feita a análise do protótipo robótico juntamente com um objeto de aprendizagem, avaliando e descobrindo a viabilidade da introdução da robótica como apoio a motivação dos estudantes na realização de atividades.

Quanto ao modo de abordagem este trabalho é caracterizado de natureza quanti-qualitativa, que investiga atitudes, valores e interpretações de fenômenos para compreender as razões e atribuir significados, dado que segue a perspectiva interpretativa e subjetiva da realidade educacional, além da inclusão de dados quantitativos para apresentação e análise dos dados, com objetivo de quantificar e generalizar os resultados obtidos (CHEMIN, 2015). 
A modalidade de pesquisa utilizada, segundo os procedimentos técnicos é estudo de caso, que caracteriza-se por ser um estudo "profundo e exaustivo" de um ou mais objetos, explorando-os de maneira ampla e detalhada (GIL, 2002), com o objetivo de analisar o problema da dificuldade do aprendizado dos estudantes na disciplina de português e identificar fatores e contribuições da robótica na solução deste. Os dados serão levantados através da observação, que utilizam os sentidos na obtenção de dados da realidade e esses fatos ou fenômenos serão analisados e serão usados no trabalho da forma descritiva, e também serão colhidos e analisados dados quantitativos, como quantidade de acertos e erros de exercícios dos estudantes (LAKATOS; MARCONI, 2003; CHEMIN, 2015). É importante coletar de dados através de mais de uma técnica, portanto será utilizada a observação espontânea e participante, além da filmagem de vídeo e análise de documentos, sendo estes atividades em papel e através das respostas das atividades no objeto de aprendizagem (GIL, 2002).

O trabalho foi dividido em cinco partes, sendo elas pesquisa bibliográfica, desenvolvimento do objeto de aprendizagem (OA) (Figura 1), construção do protótipo (Figura 2), intervenção pedagógica e análise dos resultados.

Figura 01 - Tela do OA

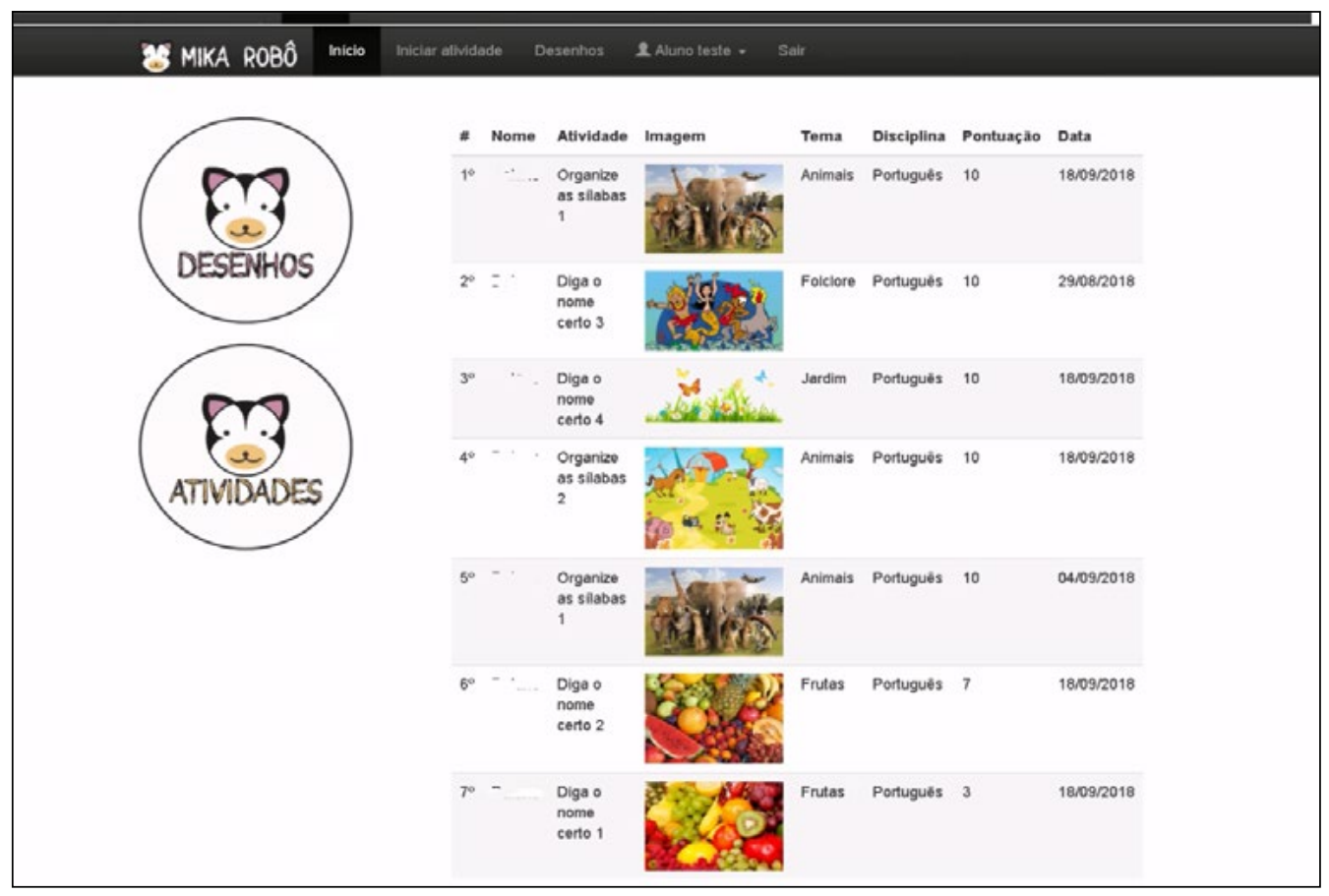

Fonte: Dos autores, 2019. 
Figura 02 - Protótipo Mika Robô

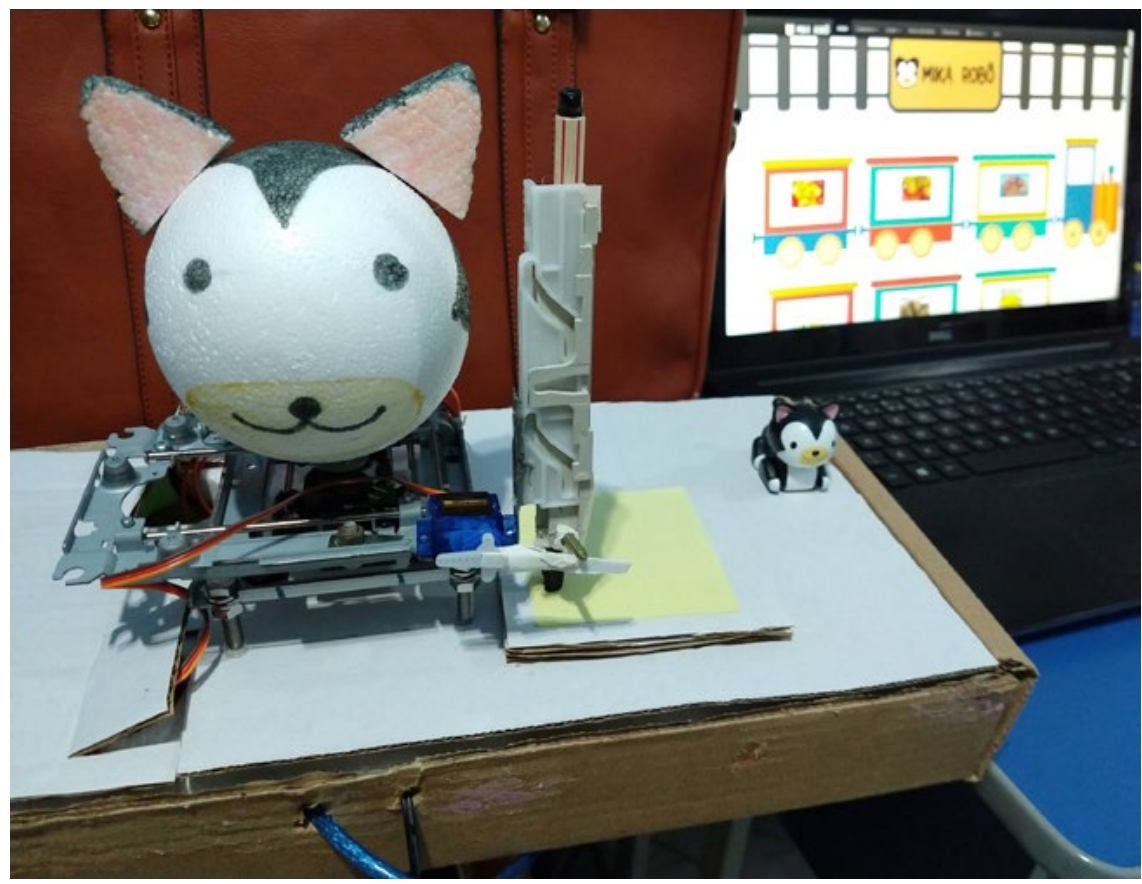

Fonte: Dos autores, 2019.

A escola na qual se realizou a prática pedagógica é uma instituição municipal, situada na cidade de Teutônia, RS. A turma envolvida, do $3^{\circ}$ ano do Ensino Fundamental, conta com sete alunos, e as atividades tiveram a duração de três dias seguidos, dois deles com o contato com a Mika Robô. A intervenção pedagógica é composta por um pré-teste, seguido para a intervenção com a Mika Robô e um pós-teste realizado no terceiro dia. As atividades em papel foram aplicadas pela professora, com duração de menos de 10 minutos. A duração da intervenção com a Mika Robô foi de aproximadamente duas horas e meia, e no último dia de cinquenta minutos.

\section{ANÁLISE E DISCUSSÃO DOS DADOS}

O computador é uma ferramenta cheia de possibilidades pedagógicas, mas também é importante e necessário que a criança compreenda a função educativa e recreativa do computador ou tecnologia, e por meio dela, desenvolva o interesse de buscar conhecimento e desenvolver o raciocínio.

De acordo com a descrição realizada na metodologia, no dia anterior a intervenção a professora da turma aplicou duas atividades em papel, o pré-teste, para avaliar o desempenho deles na escrita. No dia da intervenção, primeiramente foi explicado às crianças como são os robôs, que nem sempre 
eles têm pernas e braços, foi apresentada a mascote Mika Pet que é um robô que canta e caminha a partir de instruções de voz e que a Mika Robô faz desenhos se forem acertadas quase todas as palavras da atividade. Quando as crianças viram a Mika Robô, comentaram: "como é estranho este robô!"; "como ele é esquisito". Foi demonstrado para as crianças como se cadastrar no OA, mostrados os desenhos que podiam ganhar, mostradas as atividades e como realizar uma atividade, respondendo os exercícios, e ao fim a Mika Robô desenhando o desenho. Nesse momento as crianças já estavam em fila, para começar a resolver as atividades.

Cada aluno foi se cadastrando e realizando a primeira atividade, sendo auxiliados quando tinham dificuldades, principalmente na utilização do OA. Os alunos têm aula de informática uma vez por semana na escola, estando acostumados a escrever textos e realizar atividades no computador, contam com netbooks e computadores também em sua sala e podem utilizá-los em seus intervalos para jogar. Nessa primeira atividade, os alunos formaram uma fila, alguns ajudavam, outros brincavam com o Mika Pet ou se preocupando que a caneta ia acabar e não iam ganhar desenhos, já mostrando a motivação em relação ao uso do OA e robô. Por fim, foi realizada uma atividade, sem interferência de ninguém, pois neste momento já estavam familiarizados com o ambiente. Durante as atividades as crianças conversavam, chamando as atividades de jogos e diziam que se tivessem um robô assim, iam brincar todo dia. Ao finalizar uma atividade, viam sua nota e já contavam para sua professora, principalmente quando era um 10, e corriam para aguardar o seu desenho ser desenhado pela Mika Robô. Quando terminava de ser desenhado o desenho, o pegavam para mostrar aos colegas e comentavam o fato de ter tantos detalhes nos desenhos, de como o a Mika Robô desenhava bem. Enquanto isso, o próximo aluno já iniciava uma atividade para ganhar o seu desenho.

No dia seguinte da intervenção foi aplicado o pós-teste, onde realizaram três atividades em papel. Também foram expostas as notas dos alunos impressas em um mural na sala de aula, no qual eles puderam comparar suas notas novamente. As crianças puderam realizar uma quarta atividade no Mika Robô no dia do pós-teste. Comparando as notas no pré-teste, OA e pós-teste, temos as notas do exercício 1 de jardim (Figura 3) e exercício 2 de animais selvagens (Figura 4). Foi optado por dar números para cada estudante. Baseado nestes dados, é possível visualizar que os alunos, em média, não foram tão bem no pré-teste quanto com o OA e pós-teste. 
Figura 03 - Notas dos estudantes no exercício 1

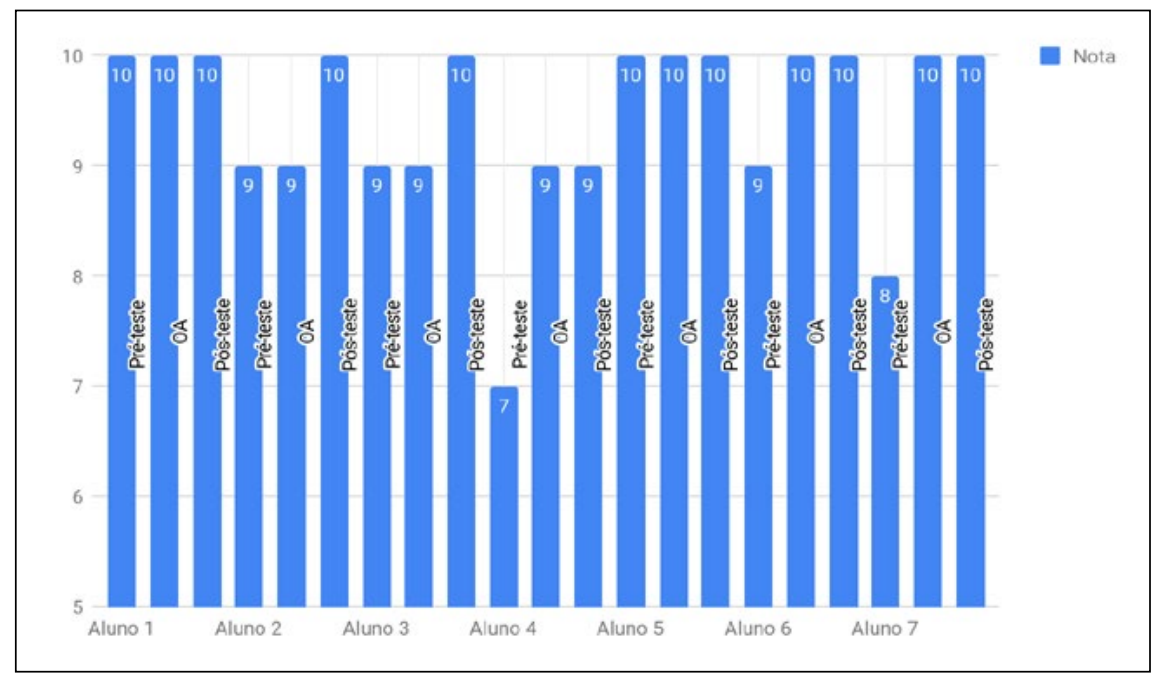

Fonte: Dos autores, 2019.

Figura 04 - Notas dos estudantes no exercício 2

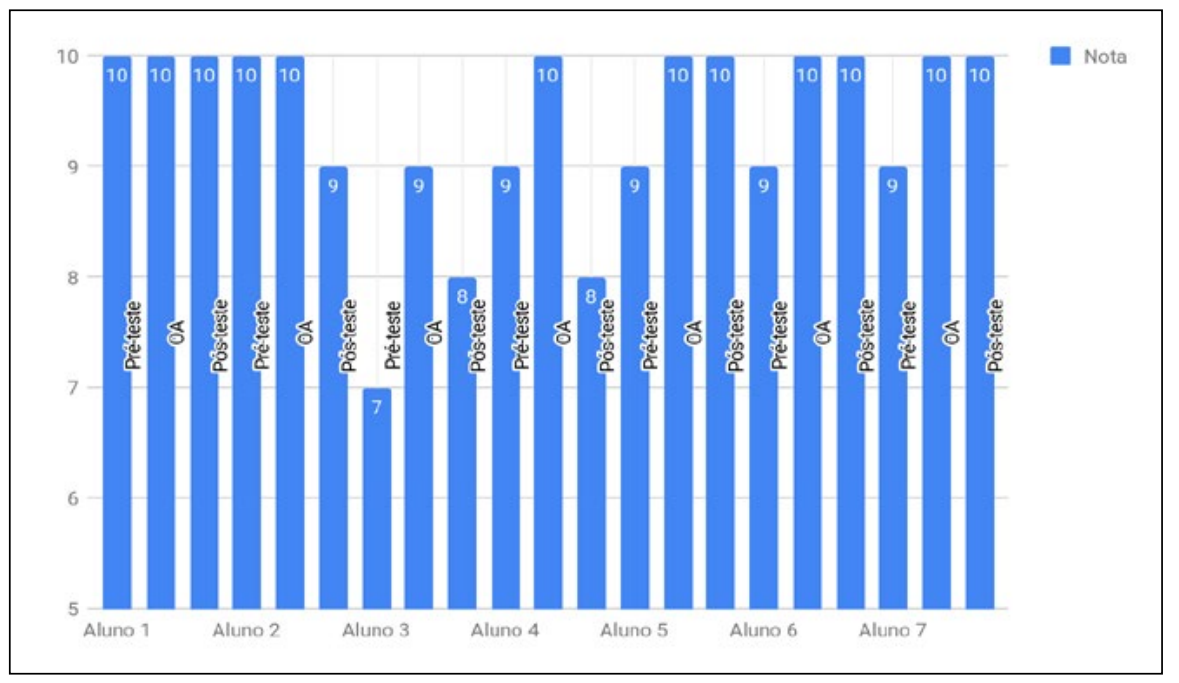

Fonte: Dos autores, 2019.

Os métodos de ensino e aprendizagem, assim como a motivação e engajamento encontrados nos jogos tem muito a contribuir para a educação formal, e é através da gamificação que isso pode ocorrer, com estratégias para a construção de experiências mais significativas (FARDO, 2013). E a gamificação da Mika Robô, ou seja, transformar ela em um jogo contribui para o aprendizado 
e motivação das crianças, principalmente devido elas perguntarem se podiam "brincar" até o final da aula, manifestando sua apreciação.

\section{CONCLUSÕES}

Nos dias de hoje a tecnologia tornou-se uma das principais formas de recreação das crianças e jovens da geração de nativos digitais. Verifica-se que as tecnologias contribuem positivamente na formação dos indivíduos desde a infância, contanto que o seu uso seja controlado e supervisionado. Utilizar o computador, tablet ou smartphone de forma saudável ou como ferramenta pedagógica é possível, e é uma alternativa que resulta em sucesso, desde que a criança desenvolva interesse em buscar conhecimento.

Usando a robótica como ferramenta motivacional com estudantes da educação básica, percebeu-se uma melhora significativa na resolução dos exercícios propostos. O pré-teste e pós-teste aplicados durante a intervenção demonstraram isso. Neste sentido é possível afirmar que a robótica deve ser cada vez mais utilizada na educação, tendo em vista que ela contribui para uma melhora no aprendizado. Juntamente com uma boa proposta pedagógica esta pode ser uma poderosa ferramenta.

Em trabalhos futuros, pretende-se aplicar e validar estes conceitos na prática em sala de aula com alunos de outros anos da educação básica além do $3^{\circ}$ ano, ou ainda em turmas de outros colégios, a fim de complementar os resultados obtidos, bem como avaliar e confirmar a motivação e melhoria no aprendizado que este estudo aponta.

\section{REFERÊNCIAS}

BARCELOS, Thiago Schumacher; SILVEIRA, Ismar Frango. Pensamento Computacional e Educação Matemática: Relações para o Ensino de Computação na Educação Básica. In: WEI - WORKSHOP SOBRE EDUCAÇÃO EM COMPUTAÇÃO, 20., 2012, Curitiba. Anais do CSBC - XXXII Congresso da Sociedade Brasileira de Computação, 2012. E-book. Disponível em: <http:/ / www.imago.ufpr.br/ csbc2012/anais_csbc/eventos/wei/artigos/Pensamento\%20Computacional $\% 20$ e\%20Educacao\%20Matematica\%20Relacoes\%20para\%20o\%20Ensino\%20de\%20 Computacao\%20na\%20Educacao\%20Basica.pdf>. Acesso em: 03 abr. 2018.

BRACKMANN, Christian Puhlmann. Desenvolvimento do pensamento computacional através de atividades desplugadas na educação básica. 2017. $226 \mathrm{f}$. Tese (Doutorado) - Universidade Federal do Rio Grande do Sul, Centro de Estudos Interdisciplinares em Novas Tecnologias na Educação, Programa de Pós-Graduação em Informática na Educação, Porto Alegre, BRRS, 2017. E-book. Disponível em: <http:/ / www.lume.ufrgs.br/handle/10183/172208>. Acesso em: 03 abr. 2018. 
CHEMIN, Beatris Francisca. Manual da Univates para trabalhos acadêmicos: planejamento, elaboração e apresentação. 3a ed. Lajeado: Ed. da Univates, 2015. E-book.

FARDO, Marcelo Luis. A gamificação como estratégia pedagógica: estudo de elementos dos games aplicados em processos de ensino e aprendizagem. 2013. $104 \mathrm{f}$. Dissertação (Mestrado) - Programa de Pós-Graduação em Educação, Universidade de Caxias do Sul, Caxias do Sul, 2013. E-book.

FRANÇA, Rozelma Soares; AMARAL, Haroldo José Costa do. Proposta Metodológica de Ensino e Avaliação para o Desenvolvimento do Pensamento Computacional com o Uso do Scratch. In: WIE - WORKSHOP DE INFORMÁTICA NA ESCOLA, 19., 2013, Campinas. Anais do CBIE - II Congresso Brasileiro de Informática na Educação, 2013. 179-188. E-book.

GIL, Antônio Carlos. Como elaborar projetos de pesquisa. 4a ed. São Paulo: Atlas, 2002.

GONÇALVES, Vitor Manuel Barrigão. Desenvolvimento de sistemas de informação para a web: um portal para as escolas do $1 .^{\circ}$ ciclo e os jardins de infância. $2002.268 \mathrm{f}$. Tese (Mestrado) - Tecnologia Multimédia, Faculdade de Engenharia, Universidade do Porto, 2003. E-book. Disponível em: < http://hdl.handle.net/10198/544>. Acesso em: Acesso em: 04 jun. 2018.

GORDINHO, Sandra Salomé Valente. Interfaces de Comunicação e Ludicidade na infância: brincriações na programação Scratch. 2009. 181 f. Dissertação (Mestrado) Design, Departamento de Comunicação e Arte, Universidade de Aveiro. 2009. E-book.

KNÜPPE, Luciane. Motivação e desmotivação: desafio para as professoras do Ensino Fundamental. Educar em Revista, n. 27, p. 277-290, 2006. Editorial Universidade Federal do Paraná. E-book. Disponível em: <http:/ / www.redalyc.org/articulo. oa?id=155013354017> . Acesso em: 18 mai. 2018.

KONRATH, Mary Lúcia Pedroso; KAMPFF, Adriana Justin Cerveira; GOMES, Fábio de Jesus Lima; CARVALHO, Marie Jane Soares; NEVADO, Rosane Aragón de; "Nós no Mundo": Objeto de Aprendizagem voltado para o $1^{\circ}$ Ciclo do Ensino Fundamental. Novas Tecnologias na Educação, v.4, n.1, 2006. E-book. Disponível em: <http:/ / www.lume.ufrgs.br/bitstream/handle/10183/13023/000580956.pdf?sequence=1>. Acesso em: 04 jun. 2018.

LAKATOS, Eva Maria; MARCONI, Marina de Andrade. Fundamentos de Metodologia Científica. 5a ed. São Paulo: Atlas, 2003.

MALIUK, Karina Disconsi. Robótica educacional como cenário investigativo nas aulas de matemática. 2009. Dissertação (Mestrado) - Ensino de matemática, Instituto de Matemática, Universidade Federal do Rio Grande do Sul. Porto Alegre. E-book. Disponível em: <http:/ /www.lume.ufrgs.br/handle/10183/17426>. Acesso em: 01 abr. 2018. 
MINISTÉRIO DA EDUCAÇÃO (MEC). BNCC: a base. Disponível em: <http:/ / basenacionalcomum.mec.gov.br/abase>. Acesso em: 11 set. 2018.

OLIVEIRA, Gabriela A.A. de; BETTIO, Raphael W. de; RODARTE, Ana P.M.; BRAZ, Jussara E.; FERRARI, Fernanda B. Grubibots educacional: jogo para o ensino de algoritmos na educação básica. In: SBIE - SIMPÓSIO BRASILEIRO DE INFORMÁTICA NA EDUCAÇÃO, 25., 2014, Dourados. Anais do CBIE - III, 2014. 584-592. E-book. Disponível em: <http://www.br-ie.org/pub/index.php/sbie/ article/view/2988/2499>. Acesso em: 01 abr. 2018.

PAIVA, Natália Moraes Nolêto de; COSTA, Johnatan da Silva. A influência da tecnologia na infância: desenvolvimento ou ameaça? Psicologia Pt. O Portal dos Psicólogos, 2015. E-book. Disponível em: <http:/ / www.psicologia.pt/artigos/textos / A0839.pdf>. Acesso em: 01 abr. 2018.

PAIVA, Deise de Lacerda; ANDRADE, Jéssica Zacarias de. A identificação das competências digitais na Base Nacional Comum Curricular para o uso das tecnologias da informação e comunicação na educação básica. In: CIET CONGRESSO INTERNACIONAL DE EDUCAÇÃO E TECNOLOGIA: EnPED - ENCONTRO DE PESQUISADORES EM EDUCAÇÃO A DISTÂNCIA, [S.1.], maio 2018. ISSN 2316-8722. E-book. Disponível em: <http:/ / cietenped.ufscar.br/ submissao/index.php/2018/article/view/381>. Acesso em: 14 set. 2018.

RIBEIRO, Célia Rosa. RobôCarochinha: Um Estudo Qualitativo sobre a Robótica Educativa no $1^{\circ}$ ciclo do Ensino Básico. 2006. 189 f. Dissertação Mestrado em Educação - Tecnologia Educativa - Universidade do Minho, Braga, 2006. E-book. Disponível em: <http:/ / repositorium.sdum.uminho.pt/handle/1822/6352>. Acesso em: 03 abr. 2018.

RIBEIRO, Célia Rosa; COUTINHO, Clara Pereira; COSTA, Manuel FM. A robótica educativa como ferramenta pedagógica na resolução de problemas de matemática no Ensino Básico. In: CISTI - CONFERÊNCIA IBÉRICA DE SISTEMAS E TECNOLOGIAS DE INFORMAÇÃO. 6., 2011, Vila Real. 440-445. E-book. Disponível em: <https:/ / repositorium.sdum.uminho.pt/handle/1822/12920>. Acesso em: 03 abr. 2018 .

SILVA, Eraylson Galdino da; BARBOSA, Aline Ferreira; NETO, Sebastião R. S.; LOPES, Renato H. O.; RODRIGUES, Ariane N. Análise de ferramentas para o ensino de Computação na Educação Básica. In: WEI, 22., 2014, Brasília. Anais do CSBC - XXXIV, 2014. E-book. Disponível em: <https://www.researchgate.net/ publication/266387618_Analise_de_ferramentas_para_o_ensino_de_Computacao_na_ Educacao_Basica?enrichId=rgreq-a19a0965a939b6fa603f541f9ce39365-XXX\&enrichSou rce=Y292ZXJQYWdlOzI2NjM4NzYxODtBUzoxNDgzNDY2MzUyOTY3NjhAMTQxM jM4MDAwMjU2Mw\%3D\%3D\&el=1_x_2>. Acesso em: 01 abr. 2018.

SOBREIRA, Elaine Silva Rocha; TAKINAMI, Olga Kikue; SANTOS, Verônica Gomes dos. Programando, Criando e Inovando com o Scratch: em busca da formação do cidadão do século XXI. In: JAIE - JORNADA DE ATUALIZAÇÃO EM INFORMÁTICA NA EDUCAÇÃO, 2., 2013, Campinas. Anais do CBIE - II, 
2013. E-book. Disponível em: <http://www.br-ie.org/pub/index.php/pie/article/ view/2592/2248>. Acesso em: 01 abr. 2018.

ZANETTI, Humberto A. P.; SOUZA, Ana L. S. de; D'ABREU, João V. V.; BORGES, Marcos A. F. Uso de robótica e jogos digitais como sistema de apoio ao aprendizado. In: JAIE, 2012, Rio de Janeiro. Anais do CBIE. 2012. 142-161. E-book. Disponível em: <http://br-ie.org/pub/index.php/pie/article/view/2345>. Acesso em: 07 abr. 2018.

ZILLI, Silvana do Rocio. A Robótica Educacional no Ensino Fundamental: Perspectivas e Prática. 2004. 89 f. Dissertação (Mestrado) - Programa de PósGraduação em Engenharia de Produção, Universidade Federal de Santa Catarina, Florianópolis, 2004. E-book. 